\title{
Effect of seasonal diet composition changes on the characteristics of the gastrointestinal tract contents of the Eurasian beaver (Castor fiber)
}

\author{
R. Miltko', B. Kowalik', A. Kędzierska', A.W. Demiaszkiewicz², N.R. McEwan³ ${ }^{3}$ A. Obidziński \\ and G. Bełżecki ${ }^{1,5}$ \\ ${ }^{1}$ The Kielanowski Institute of Animal Physiology and Nutrition, Polish Academy of Sciences, \\ Instytucka 3, 05-110 Jabłonna, Poland \\ ${ }^{2}$ Witiold Stefański Institute of Parasitology, Polish Academy of Sciences, Twarda 51/55, 00-818 Warsaw, Poland \\ ${ }^{3}$ Robert Gordon University, School of Pharmacy and Life Sciences, Garthdee Campus Robert \\ Gordon University, Aberdeen, Scotland AB10 7GJ, UK \\ ${ }^{4}$ Warsaw University of Life Sciences, Faculty of Forest, Department of Forest Botany, \\ Nowoursynowska 159, 02-776 Warsaw, Poland
}

KEY WORDS: Castor fiber, cecum, digestive tract, physicochemical parameters, season
${ }^{5}$ Corresponding author: e-mail: g. blzecki@ifzz.pl

\begin{abstract}
The goal of the study was to compare chemical and physical parameters of the content of various gastrointestinal $(\mathrm{GI})$ tract segments of adult beavers and to relate the obtained results to seasonal changes in the composition of natural diet. The study was conducted on 36 adult beavers originated from the natural environment that were captured in winter, summer and autumn. The obtained results demonstrated that $\mathrm{pH}$, redox potential (Eh), dry matter (DM), short-chain fatty acids (SCFA) and distribution of food particles varied along the beaver $\mathrm{Gl}$ tract during the year. The lowest value of $\mathrm{pH}$ was observed in stomach whereas the highest in the small intestine and cecum. The reverse pattern of changes was found for the value of redox potential. The research indicated that anaerobic conditions were predominant in the cecum and so contributed to development of microbial population. Also, the increase in the SCFA contents in the cecum and colon indicated that beavers belong both to hindgut fermenters as well as to the mixed moderate type animals. In summary, the obtained results indicated that seasonal changes in the diet composition affected physical and chemical parameters as well as microbial activity of the $\mathrm{Gl}$ tract of beaver.
\end{abstract}

\section{Introduction}

The Eurasian beaver (Castor fiber) is one of the largest herbivorous rodents adapted to the digestion of plant material. Like other herbivorous rodents and lagomorphs, beavers belong to hindgut fermenters. What is typical for these animals' gastrointestinal tract is cecum and proximal colon that function together as fermentation chamber. The digesta consists of fluid and particle fractions. In the cecum, depending on the species, the digesta is mixed or mixed and separated by the colonic separation mechanism (CSM) (Björnhag, 1987) which yield retaining the fluid fraction longer than large particles. The beaver diet is very diversified. Food diversity is strictly dependent on the vegetation period and shows seasonal variations (Krojerová-Prokešová et al., 2010; Bełżecki et al., 2018). Chemical analysis of diet 
composition also confirms such variability: winter food is characterized by a higher proportion of crude fibre than the summer diet (Bełżecki et al., 2018). Analysing the degradation of food particles in the digestive tract of dugongs (Dugong dugon), showed that low fibre food was degraded at a faster rate than high-fibre plants (Lanyon and Sanson, 2006). Likewise, it could be expected the beavers foraging in different seasons will have different digesta structure, more fragmented in summer than in winter. The digesta structure, especially particle size, has an effect on the distribution of food particles in the digestive tract (Gidenne, 1992), the rate of food digestion and short-chain fatty acid (SCFA) production (Clauss et al., 2009). Mahida and Perrin (1994) found that the concentration of SCFA in rodents was primarily affected by diet composition and its structure. During a study on the Mystromys albicaudatus diet, cited researchers have discovered that diet composition also affected the $\mathrm{pH}$ of digestive tract contents.

Therefore, we hypothesized that seasonal changes in the composition of diet will cause alterations in the physicochemical parameters of beaver gastrointestinal (GI) tract contents. In order to verify this hypothesis the study was conducted to compare physicochemical characteristics of digesta from various segments of the GI tract of adult male beavers and to relate the obtained data to seasonal changes in the composition of diet.

\section{Material and methods}

\section{Animals}

The beavers were captured with the approval of the Regional Directorate of Environmental Protection in Olsztyn, Poland (ministerial approval: RDOS-28-OOP-6631-0007-638/09/10/pj), and the experimental protocol was reviewed and approved by III Local Ethical Commission for Experiments on Animals at Warsaw University of Life SciencesSGGW (Poland) before study initiation (permission no. 11/2010). The animals used for this study and the experimental and hunting procedures have been described by Bełżecki et al. (2018). Briefly, the experiment was performed on adult male beavers which were caught in winter, summer and autumn 12 individuals in each season (36 animals in total).

\section{Sample collection and analysis}

Immediately after delivery, beavers were decapitated under full anesthesia. Then sex was deter- mined and GI tracts were removed, and then stomach, small intestine, cecum and colon were isolated. The segments were emptied from the digesta, which was mixed and divided into two parts. One of them was stored frozen $\left(-20{ }^{\circ} \mathrm{C}\right)$ for the distribution of food particles analysis, the second was filtered through four layers of gauze (1-mm pore size). In the obtained fluid fraction the $\mathrm{pH}$ and redox potential (Eh) was measured (pH meter 7011, ChemLand, Stargard Szczeciński, Poland), and then $5 \mathrm{ml}$ of collected fluid was preserved with $0.5 \mathrm{ml}$ of $85 \%$ formic acid in water, and stored at $4{ }^{\circ} \mathrm{C}$ for SCFA analysis. SCFA concentration was determined by gas chromatography (GC-2010 Shimadzu, Kyoto Japan) equipped with a flame ionization detector and a ZebronTM ZB-FFAP column (Phenomenex, Torrance, CA, USA) as described by Miltko et al. (2016b).

Food particle sizes were determined by wet sieving of 100-g digesta samples using a sieve stack on a sieve shaker (Analysette 3, Fritsch, Idar-Oberstein Germany). The digesta particles were separated into fractions according to size $(<0.5 \mathrm{~mm}, 0.5$ to $1.0 \mathrm{~mm}, 1.0$ to $2.0 \mathrm{~mm}, 2.0$ to $4.0 \mathrm{~mm},>4.0 \mathrm{~mm}$ ) as described in Pająk et al. (1997). The dry matter (DM) of GI tract and digesta of each sieve fraction was determined by drying at $105^{\circ} \mathrm{C}$ for $48 \mathrm{~h}$.

One-way analysis of variance (ANOVA) was used to determine effect of season on parameters of gut content. The significance of differences between seasons was calculated by Tukey's test. The results were considered statistically significant at $P<0.01$ and $P<0.05$. The Statistica 10.0 software package (StatSoft Inc, Tulsa, OK, USA) was used for statistical analysis.

\section{Results}

The values of $\mathrm{pH}, \mathrm{Eh}, \mathrm{DM}, \mathrm{SCFA}$ and distribution of food particles varied among the different segments of the GI tract of beaver are shown in Table 1 and Figure 1.

The $\mathrm{pH}$ and Eh changed through the length of the digestive tract. The value of $\mathrm{pH}$ in stomach digesta was the lowest (1.8-2.1), increased rapidly in the small intestine (7.0-7.3) and then decreased in the colon (6.3-6.8) indicating no effect of the season. The Eh of digesta varied from 45.3 to $281.6 \mathrm{mV}$. The highest value was observed in the stomach, while the lowest in the small intestine and cecum. These fluctuations were also not connected with the season. 


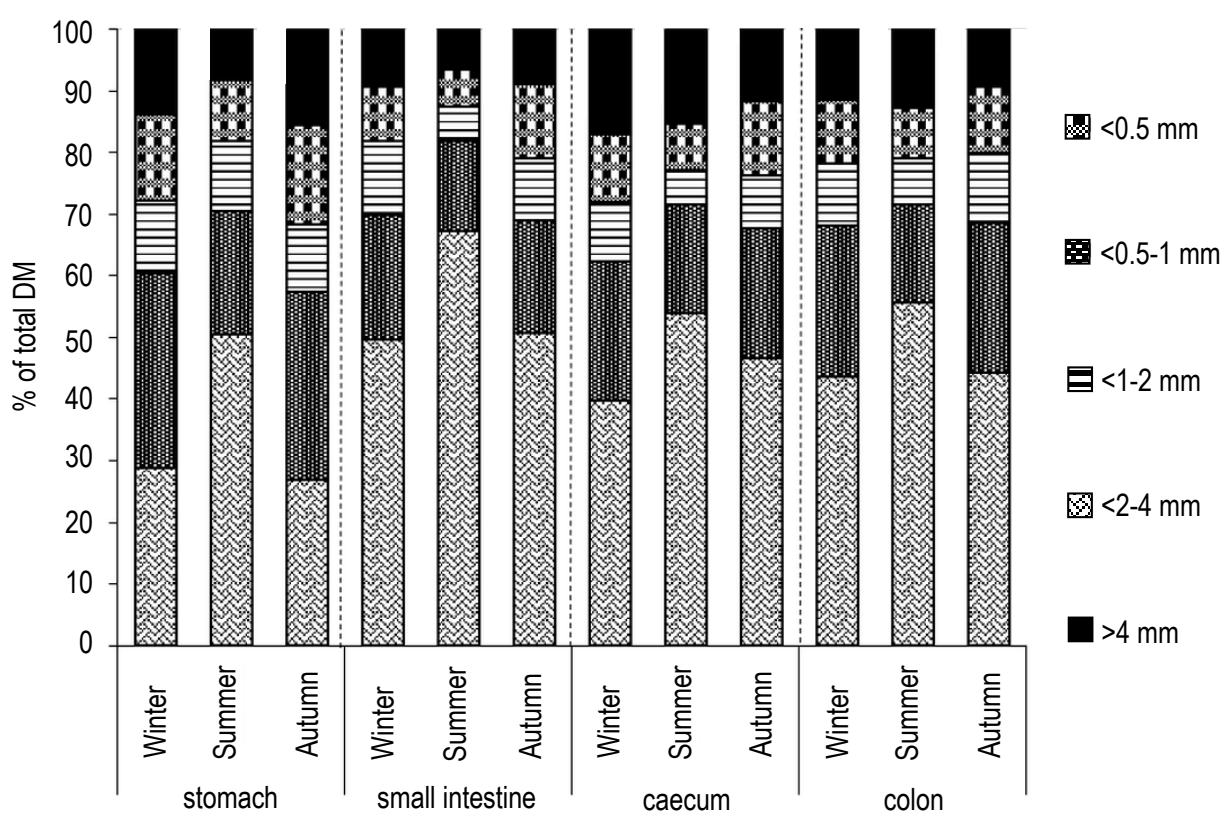

Figure 1. Particle size distributions of digesta in gastrointestinal tract segments of beavers, \% total dry matter (DM)

Table 1. Characterization of beaver digestive tract contents

\begin{tabular}{lccccc}
\hline \multirow{2}{*}{ Indices } & \multicolumn{3}{l}{ Season } & & \\
\cline { 2 - 5 } & winter & summer & autumn & & \\
\hline DM, g & & & & & \\
$\quad$ stomach & $14.4^{\mathrm{A}}$ & $10.0^{\mathrm{Ba}}$ & $13.6^{\mathrm{b}}$ & 0.549 & 0.001 \\
small intestine & $12.7^{\mathrm{A}}$ & $9.2^{\mathrm{B}}$ & 10.9 & 0.474 & 0.007 \\
cecum & $16.9^{\mathrm{a}}$ & $13.2^{\mathrm{b}}$ & 14.3 & 0.576 & 0.022 \\
colon & $28.1^{\mathrm{A}}$ & $22.8^{\mathrm{B}}$ & $22.9^{\mathrm{B}}$ & 0.749 & 0.002 \\
$\mathrm{pH}$ & & & & & \\
stomach & 1.8 & 2.1 & 2.1 & 0.088 & 0.321 \\
small intestine & 7.0 & 7.1 & 7.3 & 0.075 & 0.329 \\
cecum & $6.9^{\mathrm{A}}$ & $6.2^{\mathrm{B}}$ & 6.7 & 0.104 & 0.004 \\
colon & 6.8 & 6.3 & 6.5 & 0.087 & 0.072
\end{tabular}

Eh, $\mathrm{mV}$

$\begin{array}{lrrrrr}\text { stomach } & 194.1^{\mathrm{A}} & 144.5^{\mathrm{A}} & 45.3^{\mathrm{B}} & 13.434 & <0.001 \\ \text { small intestine } & -195.8^{\mathrm{a}} & -281.6 & -271.0^{\mathrm{b}} & 14.253 & 0.023 \\ \text { cecum } & -248.0 & -259.0 & -237.0 & 8.489 & 0.585 \\ \text { colon } & -11.1 & -16.7 & -16.0 & 5.545 & 0.909\end{array}$

SCFA, $\mu \mathrm{M} / \mathrm{g}$ contents

\begin{tabular}{lrrrrr} 
stomach & $6.1^{\mathrm{A}}$ & $7.7^{\mathrm{B}}$ & $6.7^{\mathrm{B}}$ & 0.223 & 0.001 \\
small intestine & $8.2^{\mathrm{A}}$ & $6.6^{\mathrm{B}}$ & $8.6^{\mathrm{A}}$ & 0.207 & $<0.001$ \\
cecum & $125.3^{\mathrm{A}}$ & $166.6^{\mathrm{B}}$ & $135.0^{\mathrm{A}}$ & 3.566 & $<0.001$ \\
colon & $81.4^{\mathrm{A}}$ & $135.5^{\mathrm{B}}$ & $82.0^{\mathrm{A}}$ & 4.481 & $<0.001$ \\
\hline
\end{tabular}

values in the row marked with different letters differ significantly $A, B-P<0.01 ;{ }^{a, b}-P<0.05 ;$ SEM - standard error of mean; DM - dry matter; Eh - redox potential; SCFA - short chain fatty acids

The percentage of digesta DM differed among segments. The most hydrated content was found in the stomach and in the small intestine, lower in the cecum, whereas the lowest in the colon. The percentage of the DM of the digesta contents can be described by the same pattern of fluctuation independent of seasons.

Changes in the concentrations of SCFA indicated that the highest value was observed in the summer in the cecum, whereas the lowest in the stomach during winter.

Comparison of GI tract contents in different seasons indicated that the digesta in the winter is characterized by the highest content of DM independent of the digestive segment, and furthermore showed a lowest value of $\mathrm{pH}$ in the stomach and the highest concentration of SCFA in the cecum, independent of seasons.

The profile of particle size distributions of digesta contents were examined to investigate the relationship between degree of food breakdown and the GI tract segment (Figure 1). The obtained results indicated that the food particle size distribution varied along digestive tract and was season-dependent. It was found that particles of $<0.05 \mathrm{~mm}$ (the smallestsized fraction) were predominant in all parts of the digestive tract of beavers except for the stomach in winter and autumn seasons. The highest level of the fine-size fraction was observed in the summer in the small intestine (up to $70 \%$ ), whereas the lowest was in the autumn in the stomach (about 30\%). In addition, it was found that in the summer, the fraction of $<0.5 \mathrm{~mm}$ was dominant in the stomach, which was $50 \%$ of the total DM of food particles, 
while in the winter and autumn ranged from 27 to $30 \%$. The opposite effect was observed for the largesize fraction (2-4 $\mathrm{mm}$ and $>4 \mathrm{~mm}$ ) where the highest level was observed in winter and autumn. In the small intestine a further increase in the fraction $>0.5 \mathrm{~mm}$ and a decrease in the fraction $2-4 \mathrm{~mm}$ and $>4 \mathrm{~mm}$ were observed. In the cecum and colon a drop in $<0.5 \mathrm{~mm}$ particles and increase in particle fraction of $2-4 \mathrm{~mm}$ and $>4 \mathrm{~mm}$ were noted. Additionally, the highest proportion of particle size $>4 \mathrm{~mm}$ was found in the cecum.

\section{Discussion}

The structure of the GI tract of herbivorous animals is largely determined by the type of food. Large cecum (Bełżecki et al., 2018) is characteristic for beavers and rabbits that are the best studied cecum fermenters, which suggests great similarities between these species. However, digestive physiology of beavers is not comprehensively described and understood. Therefore the goal of this study was to compare chemical and physical parameters: $\mathrm{pH}$, Eh, SCFA, DM, and describe the distribution of food particles in various segments of the GI tract of beavers.

The results of current study showed that found differences could be attributed to changes of food composition, especially the fibre content of beaver diet (Bełżecki et al., 2018). It is worth mentioning that type of coastal vegetation can also affect the composition of a beaver's diet (Janiszewski et al., 2017). However, in this study, this effect component was limited because all animal were derived from pounds where dominant of the coastal zone were willow.

Mean $\mathrm{pH}$ values of stomach digesta varied from 1.8 to 2.1 independently to season and were typical for this part of GI tract (Marounek et al., 2005; ŻarySikorska et al., 2016). These results are consistent with the findings of Kohl et al. (2013). In the small intestine the $\mathrm{pH}$ value was significantly higher than in the stomach, and also in accordance with the results obtained by Juśkiewicz et al. (2012), Marounek et al. (2005) and Żary-Sikorska et al. (2016). This significant increase is caused by the secretion of the strongly alkaline pancreatic juice. The $\mathrm{pH}$ values in cecum and colon were reduced in the summer when the amount of fibre from food is the lowest (Bełżecki et al., 2018).

The mean values of the Eh detected in cecum of beaver varied from -237 to $-259 \mathrm{mV}$, and were lower in comparison to the value of Eh found in cecum of rabbits. The low Eh value is necessary to obtain optimal conditions for development of anaerobic population of microorganisms (Michelland et al., 2010) and intensive digestive as well as fermentation processes (Miltko et al., 2016a).

The fluctuations of DM of the GI tract contents of the beavers was consistent with the results of Marounek et al. (2005) who worked on digestive physiology of coypu and rabbits. Investigating the impact of the season on digesta composition, it was found that digesta DM content increased in winter. It can be the result of a different diet composition, associated with the domination of easily digested grasses and herbs in summer and woody shoots in autumn and winter (Bełżecki et al., 2018).

SCFA were present in all segments of the digestive tract of beavers. The SCFA concentration in stomach was relatively low; the similar results were obtained by Mahida and Perrin (1994) during the studies on Mystromys albicaudatus. The stomach of this species is divided in two parts. In the first called 'forestomach', the $\mathrm{pH}$ value is relatively high (Kohl et al., 2013) and so microbial growth and SCFA production are possible. In the second part named 'glandular', the $\mathrm{pH}$ value is too low to maintain microbial development, thus all SCFA present in the stomach are produced by the microorganisms living in 'forestomach'. In contrast to M. albicaudatus, the beaver stomach is composed of single chamber of large volume (Bełżecki et al., 2018). There, it is possible that there is an area where the $\mathrm{pH}$ value is suitable for growth of microbial population and microbial fermentation. Moreover, the measurement of SCFA concentration in GI tract of beaver indicated the highest concentration in cecum and then in colon.

In addition, it was found that the concentrations of SCFA were influenced by season. Significant increase of concentration in the cecum and the colon was observed during the summer. It was probably caused by differences in the food composition. It was also observed that cecum to colon ratio of SCFA concentration changed from 1.6 in winter and autumn to 1.2 in summer. This shift could result from more intensive fermentation in the colon and could be affected by higher contents of easily digestible carbohydrates in this part of GI tract.

The distribution of food particles in the beaver GI tract varies along its length. Such differences have been previously observed in hares (Naumova et al., 2015) and dugongs (Lanyon and Sanson, 2006). In the beaver stomach particles of $<1 \mathrm{~mm}$ 
were dominant and constituted up to $60 \%$ of total DM particles. The similar proportion was found in hares (Naumova et al., 2015). The opposite pattern was observed in dugongs, where particles of $>1 \mathrm{~mm}$ were the most common (Lanyon and Sanson, 2006). Probably, this disappearance is connected with different structure of dental apparatus and the technique of foraging of the dugongs (Lanyon and Sanson, 2006) and lagomorphs (Müller et al., 2014). Secondly, these animals represent different food preferences. The dugong diet is composed mainly of aquatic plants, which are less fibrous then plants in the diets of rodents and lagomorphs (Lanyon and Sanson, 2006).

In the second part of the digestive tract of beaver, i.e. in the small intestine, increased amount of the fine-size fraction $(<0.5 \mathrm{~mm})$ was found. Enzymes produced by the cells lining the gut and associated organs as well as faster transfer of larger particles could be responsible for the observed reduction of particle size.

The proportion of large-sized particles $(>4.00 \mathrm{~mm})$ was the highest in cecum in comparison to small intestine and colon. It presumably suggests that beavers belong to moderate selective type of cecum fermenters (Sakaguchi, 2003). However, further experiments should be carried out to confirm this assumption.

In addition, it was shown that percentage of fine-size particles $(<0.5 \mathrm{~mm})$ was the highest in the summer when fresh, green grass or herbs predominated, while in autumn and winter the fraction of $>0.5 \mathrm{~mm}$ particles increased and it was associated with large consumption of woody shoots (Bełżecki et al., 2018).

\section{Conclusions}

In summary, the current study indicated the effect of food composition on physicochemical features of the digesta of beaver gastrointestinal (GI) tract. Moreover, the observed seasonal variations suggest that food components exert an influence on activity of microorganisms inhabiting beaver GI tract. Nonetheless, further research is required to confirm this assumption.

\section{Acknowledgement}

This study was supported by a grant from the National Science Centre, grant No. NN 311510139. The authors are grateful to Jan Goździewski from the Polish Hunting Association in Suwałki for capturing and delivery of animals.

\section{References}

Bełżecki G., Miltko R., Kowalik B., Demiaszkiewicz A.W., Lachowicz J., Giżejewski Z., Obidziński A., McEwan N.R., 2018. Seasonal variations of the digestive tract of the Eurasian beaver Castor fiber. Mamm. Res. 63, 21-31, https://doi.org/10.1007/s13364017-0337-X

Björnhag G., 1987. Comparative aspects of digestion in the hindgut of mammals. The colonic separation method (CSM). Dtsch. Tierarztl. Wschr. 94, 33-36

Clauss M., Nunn C., Fritz J., Hummel J., 2009. Evidence for a tradeoff between retention time and chewing efficiency in large mammalian herbivores. Comp. Biochem. Physiol. A 154, 376-382, https://doi.org/10.1016/j.cbpa.2009.07.016

Gidenne T., 1992. Effect of fibre level, particle size and adaptation period on digestibility and rate of passage as measured at the ileum and in the faeces in the adult rabbit. Br. J. Nutr. 67, 133-146, https://doi.org/10.1079/BJN19920015

Janiszewski P., Kolasa S., Strychalski J., 2017. The preferences of the European beaver Castor fiber for trees and shrubs in riparian zones. App. Ecol. Environ. Res. 15, 313-327, https://doi. org/10.15666/aeer/1504_313327

Juśkiewicz J., Żary-Sikorska E., Zduńczyk Z., Król B., Jarosławska J., Jurgoński A., 2012. Effect of dietary supplementation with unprocessed and ethanol-extracted apple pomaces on caecal fermentation, antioxidant and blood biomarkers in rats. Br. J. Nutr. 107, 1138-1114, https://doi.org/10.1017/ S0007114511004144

Kohl K.D., Stengel A., Samun-Blank M., Dearing M.D., 2013. Effects of anatomy and diet on gastrointestinal pH in rodents. J. Exp. Zool. 319A, 225-229, https://doi.org/10.1002/jez.1786

Krojerová-Prokešová J., Barančeková M., Hamšíková L., Vorel A., 2010. Feeding habits of reintroduced Eurasian beaver: spatial and seasonal variation in the use of food resources. J. Zool. 281, 183193, https://doi.org/10.1111/j.14697998.2010.00695.x

Lanyon J.M., Sanson G.D., 2006. Mechanical disruption of seagrass in the digestive tract of the dugong. J. Zool. 27, 277-289, https://doi.org/10.1111/j.1469-7998.2006.00135.x

Mahida H., Perrin M.R., 1994. The effect of different diets on the amount of organic acid produced in the digestive tract of Mystromys albicaudatus. Acta Theriol. 39, 21-27, https://doi. org/10.4098/AT.arch.94-3

Marounek M., Skřivan M., Březina P., Hoza I., 2005. Digestive organs, caecal metabolites and fermentation pattern in coypus (Myocastor coypus) and rabbits (Oryctolagus cuniculus). Acta Vet. Brno 74, 3-7, https://doi.org/10.2754/avb200574010003

Michelland R.J., Combes S., Monteils V., Cauquil L., Gidenne T., Fortun-Lamothe L., 2010. Molecular analysis of the bacterial community in digestive tract of rabbit. Anaerobe 16, 61-65, https://doi.org/10.1016/j.anaerobe.2009.05.002

Miltko R., Bełżecki G., Kowalik B., Skomiał J., 2016a. Presence of carbohydrate-digesting enzymes throughout the digestive tract of sheep. Turk. J. Vet. Anim. Sci. 40, 271-277, https:// doi.org/10.3906/vet-1507-70

Miltko R., Rozbicka-Wieczorek A., Więsyk E., Czauderna M., 2016b. The influence of different chemical forms of selenium added to the diet including carnosic acid, fish oil and rapeseed oil on the formation of volatile fatty acids and methane in the rumen, and fatty acid profiles in the rumen content and muscles of lambs. Acta Vet. Beograd 66, 373-391, https://doi. org/10.1515/acve-2016-0032 
Müller J., Clauss M., Codron D., Schulz E., Hummel J., Fortelius M., Kircher P., Hatt J-M., 2014. Growth and wear of incisor and cheek teeth in domestic rabbits (Oryctolagus cuniculus) fed diets of different abrasiveness. J. Exp. Zool. 321A, 283-298, https://doi.org/10.1002/jez.1864

Naumova E.I., Zharova G.K., Chistova T.Yu., Kuznetsova T.A., 2015. The effect of coprophagy on the size of plant fibers in the digestive tract of hares Lepus europaeus and L. timidus (Lagomorpha, Leporidae). Biol. Bull. Russ. Acad. Sci. 42, 426-431, https://doi.org/10.1134/S106235901505009X

Pajak J.J., Żebrowska T., Długołęcka Z., Korczyński M., 1997. Particle size distribution and outflow rate from the rumen of cows fed rations with different protein sources. J. Anim. Feed Sci. 6, 471-484, https://doi.org/10.22358/jafs/69559/1997
Sakaguchi E., 2003. Digestive strategies of small hindgut fermenters. Anim. Sci. J. 74, 327-337, https://doi.org/10.1046/j.13443941.2003.00124.x

Żary-Sikorska E., Juśkiewicz J., Jundziłł A., Rybka J., 2016. Effect of diets varying in the type of dietary fibre and its combination with polyphenols on gut function, microbial activity and antioxidant status in rats. J. Anim. Feed Sci. 25. 250-258, https://doi. org/10.22358/jafs/65560/2016 